\title{
A comparative study between prostaglandin F2 $\alpha$ and methyl ergometrine in the active management of third stage of labour
}

\author{
Sabha Malik, Cimona, Fida Mohammad \\ Correspondence: Sabha Malik, Department of Obstetrics and Gynaecology, Sher-i-Kashmir \\ Institute of Medical Sciences, Srinagar, Jammu \& Kashmir, India; Email - \\ mohammedsarwarmir@gmail.com
}

Distributed under Creative Commons Attribution-Share Alike 4.0 International.

\begin{abstract}
Background: Post-partum hemorrhage (PPH) which occurs in up to $18 \%$ of the births carries with it a $3 \%$ risk of death and is a largely preventable event. Material and Methods: A prospective study was carried out over a period of one and half years. A total of 200 women were enrolled in the study and were divided into two groups. In Group I prostaglandin F2 $\alpha$ was given intramuscularly and in group II methyl ergometrine was given intravenously at the time of delivery of anterior shoulder of the fetus. The main outcome measures that were studied included the duration of third stage of labour, amount of blood loss and a drop in hemoglobin and haematocrit concentration from before delivery to $24 \mathrm{hrs}$ after delivery. Results: It was observed that the mean duration of third stage of labour was significantly shorter ( $\mathrm{p}<0.001)$ in Group I $(2.52 \pm 1.35$ mins) as compared to Group II ( $3.41 \pm 1.1$ mins). The mean blood loss was also significantly less $(p<0.001)$ in the Group I $(129 \pm 27.25$ $\mathrm{ml})$ as compared to Group II ( $250 \pm 35.21 \mathrm{ml})$. The percentage drop in hemoglobin in Group I was significantly lesser than in Group II. Conclusion: It was concluded that intramuscular prostaglandin F2 $\alpha$ is a better alternative to intravenous methyl ergometrine in the active management of third stage of labour as it reduces blood loss significantly.
\end{abstract}

Keywords: Uterotonics, labor, post-partum hemorrhage, methyl ergometrine, prostaglandin F2 $\alpha$.

Post-partum hemorrhage (PPH) which occurs in up to $18 \%$ of the births carries with it a $3 \%$ risk of death and is a largely preventable event ${ }^{1}$. Post-partum hemorrhage $(\mathrm{PPH})$ is the most serious complication in obstetric practice. The greatest number of maternal deaths from hemorrhage is due to $\mathrm{PPH}$, which is almost entirely a preventable condition. PPH occurs in approximately $4 \%$ of vaginal deliveries, and estimates are that it causes significant morbidity and $25 \%$ of all the maternal child birth related deaths ${ }^{2}$. The WHO defines PPH as blood loss of $500 \mathrm{ml}$ or more in first $24 \mathrm{~h}$ postpartum ${ }^{3}$. Postpartum blood loss is difficult to evaluate especially in developing country like India where most of the women are anaemic with poor reserve and this conditions are further aggravated by increased demand during pregnancy and blood loss during 3 rd stage of labor ${ }^{4}$. The days of expectant management, the so called "hands off" 5 approach seems to be over, in view of serious

Received: $30^{\text {th }}$ December 2017. Accepted: $26^{\text {th }}$ January 2018.

Malik S, Cimona, Mohammad F. A comparative study between prostaglandin F2 $\alpha$ and methyl ergometrine in the active management of third stage of labour. The New Indian Journal of OBGYN. 2018; 5(1): 13-17. 
consequences of PPH.

Active management of labour is associated with two to three fold decreases in the risk of PPH. It includes use of oxytoxics with the delivery of anterior shoulder of the baby, early cord clamping and delivery of placenta by controlled cord traction. Oxytocin and methyl ergometrine are commonly used uterotonics for prevention of $\mathrm{PPH}$. The importance of prostaglandin use for the treatment of $\mathrm{PPH}$ even after failure of conventional treatment is well established.15 methyl Prostaglandin $2 \alpha$ is well used at the time of delivery complement physiological process during labour by causing simulation of uterine contractions and results in duration of third stage of labour and thus reduction in blood loss 6 .

In present study, an attempt was made to study the efficacy and safety of intramuscular Prostaglandin $2 \alpha$ versus intravenous Methyl Ergometrine in active management of third stage labor, at the Post Graduate Department of Obstetrics and Gynecology, Sher-iKashmir Institute of Medical Sciences, Srinagar.

\section{Materials and Methods}

A prospective study was carried out in the Post Graduate Department of Obstetrics and Gynecology, Sher-i-Kashmir Institute of Medical Sciences, Srinagar from $1^{\text {st }}$ April, 2017 to $31^{\text {st }}$ September, 2017. A total 200 women were enrolled in the study. Women were randomized to one of the 2 groups once they fulfilled all the selection and exclusion criteria. Active management of 3rd stage of labor was done in Group I with intramuscular Prostaglandin $2 \alpha$ (125 microgram) and in Group II with intravenous methyl ergometrine $(0.2 \mathrm{mg})$.

Table 1: Duration Group II

\begin{tabular}{lllll}
\hline $\begin{array}{l}\text { Duration } \\
\text { of third } \\
\text { stage( in } \\
\text { minutes) }\end{array}$ & Parity & $\begin{array}{l}\text { Group-I } \\
\text { (Prostaglandin }\end{array}$ & $\begin{array}{l}\text { Group-II } \\
\text { (Methyl } \\
\text { ergometrine ) } \\
\text { (n=100) }\end{array}$ & P Value \\
\hline & P2 $\boldsymbol{\alpha})$ & $3.22 \pm 0.92$ & 0.000657 \\
& & $(\mathbf{n = 1 0 0 )}$ & $3.61 \pm 1.2$ & 0.000434 \\
& Multigravida & $2.61 \pm 1.5$ & $3.41 \pm 1.1$ & 0.000065 \\
\hline
\end{tabular}

abnormalities, history of medical disorderasthma/epilepsy/heart or renal disease were excluded from the study.

On admission to labor room, hemoglobin levels were determined. All the women were followed and monitored through the 1st and 2nd stage of labor. Time interval between the delivery of the baby and the placenta was noted. Duration of the 3rd stage was thus calculated. Pulse rate, temperature and blood pressure were recorded 1 hour after delivery. Amount of blood loss was calculated by weighing the gauzes/sponges before delivery followed by again weighing them after delivery. Patient was kept in labor room under observation for a period of 2 hours any complaint such as nausea, vomiting, fever, headache, chills, diarrhoea and shivering was noted. Repeat hemoglobin estimation was done 2 nd post-partum day after 24 hours.

The statistical analysis was performed using student's $\mathrm{t}$ test. $\mathrm{P}$ value of $<0.001$ was considered statistically significant. Data were calculated as means, standard deviations (SD), numbers and frequency (\%).

\section{Results}

A total of two hundred women were studied during the research period. Mean duration of third stage of labor was significantly shorter in Group I as compared to the Group

of third stage of labour (in minutes) in Group $I$ and

Inclusion criteria: Women with singleton pregnancy, between 37 and 42 week of gestation, anticipated vaginal delivery, vertical lie, no high risk factors and ready to give written and informed consent were enrolled in the study.

Exclusion Criteria: Women with hemoglobin $6 \mathrm{gm} \%$ and above, pregnancy induced hypertension, abruption placentae/marginal placenta previa/low lying, placenta, multiple pregnancy, grand multipara, malpresentation, polyhydramnios, previous uterine scar, chorioamnionitis, prolonged labor, intra uterine fetal death, coagulation
II (2.52 \pm 1.35 minutes in group I vs $3.41 \pm 1.1$ minutes in Group II) ( Table 1 ). The mean blood loss was Table 2: Blood loss (ml) in group I and Group II

\begin{tabular}{llll}
\hline Parity & $\begin{array}{l}\text { Group-I } \\
\text { Prostaglandin } \\
\text { F2 } \alpha \\
(\mathbf{n}=\mathbf{1 0 0})\end{array}$ & $\begin{array}{l}\text { Group-II } \\
\text { (Methyl } \\
\text { ergometrine })\end{array}$ & P Value \\
$\mathbf{( n = 1 0 0 )}$ & \\
\hline Primipara & $124 \pm 34.55$ & $256 \pm 36.65$ & 0.000021 \\
Multipara & $134 \pm 24.43$ & $253 \pm 34.58$ & 0.000156 \\
Total & $129 \pm 27.25$ & $250 \pm 35.21$ & 0.000698 \\
\hline
\end{tabular}


significantly less in Group I $(129 \pm 27.25 \mathrm{ml})$ than in

Table 3: Pre and post delivery haematocrit in Group 1 and Group II

\begin{tabular}{llll}
\hline Group & Status & Haematocrit & P value \\
\hline $\begin{array}{l}\text { Group I (Prostaglandin } 2 \alpha) \\
(\mathrm{n}=100)\end{array}$ & $\begin{array}{l}\text { Pre delivery } \\
\text { Post delivery }\end{array}$ & $29.6 \pm 3.4$ & 0.128 \\
$\begin{array}{l}\text { Group II (Methyl ergometrine ) } \\
(\mathrm{n}=100)\end{array}$ & $\begin{array}{l}\text { Pre delivery } \\
\text { Post delivery }\end{array}$ & $32.6 \pm 3.1$ & \\
$26.5 \pm 2.5$ & 0.00098 \\
\hline
\end{tabular}

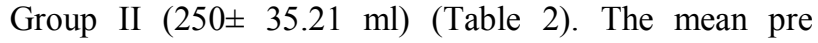
delivery haematocrit and the mean post delivery haematocrit in group I was $29.6 \pm 3.24$ and $27.5 \pm 2.5$ respectively. The difference was found to be statistically insignificant. The mean pre delivery haematocrit and the mean post delivery haematocrit in group II was $32.6 \pm 3.1$ and $26.5 \pm 2.5$ respectively. The difference was found to be

deaths worldwide and in India is post partum hemorrhage. It is mostly caused by uterine atony. It is the excessive blood loss i.e., more than $500 \mathrm{ml}$ in vaginal delivery and more than $1,000 \mathrm{ml}$ in cesarean section. The factors that predispose to PPH include a history of postpartum hemorrhage in previous pregnancy, prolonged, augmented or rapid labor, pre eclampsia, operative delivery, chorioamnionitis, trauma to the genital tract i.e., large episiotomy,

\begin{tabular}{|c|c|c|c|c|c|}
\hline Group & Status & $\begin{array}{l}\text { Hemoglobin } \\
\text { (Hb) }\end{array}$ & $\begin{array}{l}\text { \% drop in } \\
\mathrm{Hb}\end{array}$ & $\begin{array}{l}\text { Absolute } \\
\text { drop in } \mathbf{H b}\end{array}$ & P value \\
\hline $\begin{array}{l}\text { Group 1(PGF 2 } \alpha) \\
(\mathrm{n}=100)\end{array}$ & $\begin{array}{l}\text { Pre delivery } \\
\text { Post delivery }\end{array}$ & $\begin{array}{l}10.42 \pm 1.2 \\
9.64 \pm 0.76\end{array}$ & $3.74 \pm 1.95$ & $0.47 \pm 0.32$ & 0.08762 \\
\hline $\begin{array}{l}\text { Group II } \quad \text { (methyl } \\
\text { ergometrine })(n=100)\end{array}$ & $\begin{array}{l}\text { Pre delivery } \\
\text { Post delivery }\end{array}$ & $\begin{array}{l}10.62 \pm 0.72 \\
8.64 \pm 0.66\end{array}$ & $6.97 \pm 2.95$ & $0.87 \pm 0.32$ & $<0.000065$ \\
\hline
\end{tabular}

laceration of perineum or an over distended uterus due to macrosomia, twins or hydramnios and coa-

statistically significant (Table 3). The mean pre delivery hemoglobin and the mean post delivery hemoglobin in group I was $10.42 \pm 1.2$ and $9.64 \pm 0.76$ respectively. The difference was found to be statistically insignificant. The mean pre delivery hemoglobin and the mean post delivery hemoglobin in group II was $10.62 \pm 0.72$ and $8.64 \pm 0.66$

Table 5: Side effects in Group I and II (in \%, $n=100$ )

\begin{tabular}{|c|c|c|c|}
\hline $\begin{array}{l}\text { Side } \\
\text { effects }\end{array}$ & $\begin{array}{l}\text { Group 1 } \\
\text { (Prostaglandins } \\
\text { F2a) }\end{array}$ & $\begin{array}{l}\text { Group II } \\
\text { (Methyl } \\
\text { ergometrine ) }\end{array}$ & P value \\
\hline Nausea & 24 & 14 & 0.000876 \\
\hline Vomiting & 12 & 6 & 0.000765 \\
\hline Diarrhoea & 2 & 0 & 0.000987 \\
\hline Shivering & 6 & 14 & 0.000187 \\
\hline Pyrexia & 4 & 0 & 0.00015 \\
\hline
\end{tabular}

respectively. The difference was found to be statistically significant (Table 4). Among the side effects (Table 5) nausea was the most common side in Group I patients present $24 \%$ of the patients while as it was present in only gulation defects. Many of these risk factors can be identified during the antenatal/prenatal care or in early labour so that, ideally, women are referred to a health facility where prophylaxis and treatment are available. ${ }^{7}$

Prostaglandins are considered to be the physiological stimuli for myometrial contractility. Prostaglandin $2 \alpha$ causes dose dependent increase in uterine tone as well as frequency and amplitude of uterine contractions. It is highly effective drug in the management of massive bleeding. Common side effects of prostaglandins include fever, vomiting, diarrhoea and excessive uterine contractions. Care should be taken in women with asthma (can cause bronchospasm) and glucoma (raise intraocular pressure). In patients with existing cardiovascular dysfunction, they can lead to cardio-respiratory failure ${ }^{7}$.

Methyl ergometrine is a semisynthetic ergot alkaloid derivative. Uterotonic action is seen immediately after intravenous administration. It is used alone or on in combination with oxytocin in the prevention and treatment of PPH. The intensity of pressor response is enhanced when the blood pressure is already elevated, 
therefore it is contraindicated in women with hypertension ${ }^{7}$.

In present study, an attempt was made to study the efficacy and safety of intramuscular prostaglandin $2 \alpha$ versus intravenous methyl ergometrine in active management of third stage labor. The main outcome measures that were studied included the duration of third stage of labour, amount of blood loss and a drop in hemoglobin and haematocrit concentration from before delivery to 24 hours after delivery.

In present study the mean duration of third stage and amount of blood loss after delivery was found significantly lower in group I (prostaglandins $2 \alpha$ ) in comparison to methyl ergometrine group. Significant reduction duration of third stage of labor and amount of blood loss was also observed by Devi et $\mathrm{al}^{8}$, Bhattacharya et $\mathrm{al}^{9}$ and Nagaria $\mathrm{T}$ et $\mathrm{al}^{10}$. Abdel Aleem et al ${ }^{11}$ studied and reported similar observations while comparing two drugs in prevention of atonic PPH. Lamba et al ${ }^{12}$ in 2014 found prostaglandins were associated with least blood loss compared to oxytocin and methyl ergometrine. Shreatha et al ${ }^{13}$ also observed that prostaglandins were better in reducing duration of third stage as compared to methyl ergometrine.

It was observed in our study that in prostaglandin group, the post delivery mean absolute and mean percentage fall in hemoglobin was significantly lower supporting the fact that prostaglandins reduce the amount of blood loss when given during third stage of labour. Purshottam et $\mathrm{al}^{14}$ also reported the same findings who reported that mean fall in $\mathrm{Hb} \%$ to be less in prostaglandin group compared to the methyl ergometrine group.

Nausea and vomiting were more group I as compared to group II. Similar results were observed by Nageria et $\mathrm{al}^{10}$. Anjanayelu et $\mathrm{al}^{15}$ and Bhatacharya et al ${ }^{9}$ reported diarrheoa as the most common side effect with vomiting in $2 \%$ of the cases who received prostaglandins. Ebourne et $\mathrm{al}^{16}$ reviewed various studies and concluded that prostaglandins are superior to ergot alkaloids and oxytocin because it was less likely predispose to retained placenta and oxytocin had higher potential to cause water retention.

\section{Conclusion}

Prostaglandin $2 \alpha$ is a safe and efficacious drug in the management of third stage of labour. When used as prescribed and judiciously it causes significant reduction in the blood loss which makes it so important especially in the developing countries like India where large numbers of women are anaemic and may develop serious life threatening problems even with moderate amount of it blood loss. It can contribute to greater extent in reducing maternal mortality and morbidity in developing countries like India by reducing post partum hemorrhage, anemia and associated problems. However larger scale studies are required to confirm the same and usage of uterotonics especially in women with co-morbidities needs further research for optimal management in third stage of labour in these women.

\section{Conflict of interest: None. Disclaimer: Nil.}

\section{References}

1.Anderson JM, Itches D. Prevention and management of Post partum hemorrhage. Am Fam Physician. 2007 Mar 15; 75(6): 875-82.

2.Maughan KL, Heim SW, Galazka SS. Preventing postpartum hemorrhage: managing the third stage of labour. AAFP. 2006; 73(6):1025-8.

3.Fenton JJ, Baumeister LM, Fogarty J. Active management of third stage of labour among American Indian women. Fam Med. 2005; 37(6): 410-4.

4.Justus Hofmeyr G, Sandra Ferreira V, Nikodem C, et al. Misoprostol for treating post partum hemorrhage: a randomized controlled trial [ISRCTN72263357]. BMC Pregnancy childbirth. 2004; 4: 16.

5.Prendiville WJ, Elbourne D, Mc Donald S. Active versus expectant management in third stage of labour. Cochrane Database system Rev. 2000; 3: CD000007.

6.Kumari R, Mendiratta SL, Kumari P, Renu. Comparison of efficacy and safety of I/M PGF $2 \alpha$ versus I/V Methyl Ergometrine in the Active Management of third Stage of Labour. Indian obstetrics and Gynaecology. 2015; 5(1):1922.

7.Gupta A. Comparative study of methyl ergonovine and 15 methyl prostaglandin in active management of third stage of labor. Obstet Gynecol sci. 2013 Sep; 56(5): 301-306

8.Devi PK, Sutaria VD, Raghavan KS. Prophylactic use of 15 PGF 2 alpha for control of post partum bleeding. Acta Obstet Gynecol Scand. 1988; 145 suppl: S7-8.

9.Bhattacharya P, Devi PK, Jain S. Prophylactic use of 15 methyl PGF 2 alpha by intramuscular route for control of post partum bleeding - a comparative trial with methyl 
The New Indian Journal of OBGYN. 2018 (July-December); 5(1)

ergometrine. Acta Obstet Gynecol Scand. 1988;145 suppl: S 13-5.

10.Nagaria T, Ekka M. Intramuscular PGF 2 alpha $125 \mathrm{~g}$ versus intravenous methyl ergometrine $0.2 \mathrm{mg}$ in the active management of third stage of labour. Obstet Gynecol India. 2006 Sept-Oct; 56(4): 396-98.

11.Abdel-Aleem H, Abol-Oyoun EM, Moustafa SA, Kamel HS, Abdel-Wahab HA. Carboprost trometamol in the management of third stage of labour. International J Gynecol Obstet. 1993 Sep: 42(3); 247-50.

12.Lamba A, Joshi G, Purohit RC. Comparison of oxytocin, methergin and carboprost in active management of third stage of labour. International journal of Medical sciences. 2013; 6(2): 65-8.

13.Shrestha A, Urala MS, Upreti D, Niraula S. Comparison of intramyometrial and intramuscular 15 methyl PGF 2 against traditionally used intramuscular methergin for active management of third stage of labor. NJOG. 2008 Nov-Dec; 3(2): 35-9.
14.Purshottam BJ. I/M PGF $2 \alpha$ versus I/V methyl ergometrine for prevention of atonic $\mathrm{PPH}$ in high risk women. J Obstet Gynecol India. 2008 Sep-Oct; 58(5); 41720 .

15.Anjanaeyulu R. Prophylactic use of 15 methyl PGF 2 by intramuscular route -a controlled clinical trial. Acta obstet Gynecol Scand. 1988; 145 Suppl: 59-11.

16.Elbourne D. Choice of oxytocics preparation for routine use in the management of the third stage of labour an overview of evidence from controlled trials. Br J O Gynecol. 1988; 95; 17-30.

Sabha Malik ${ }^{1}$, Cimona ${ }^{2}$, Fida Mohammad ${ }^{3}$

${ }^{1}$ Senior Resident, ${ }^{2}$ Associate Professor, Department of Obstetrics and Gynaecology, Sheri-Kashmir Institute of Medical Sciences, Srinagar, Jammu \& Kashmir, India; ${ }^{3}$ Medical Officer, JLMN Hospital, Srinagar, Jammu \& Kashmir, India. 